\title{
Erratum to: DPP-4 inhibitors in diabetic complications: role of DPP-4 beyond glucose control
}

\author{
Eun Ju Bae ${ }^{1}$
}

Published online: 7 September 2016

(C) The Pharmaceutical Society of Korea 2016

Erratum to: Arch. Pharm. Res. (2016)

\section{9:1114-1128 \\ DOI 10.1007/s12272-016-0813-x}

Regrettably, the labeling of the last image, 'Diabetic neuropathy,' in Fig. 1, is missing in the published article. The corrected figure is shown in this erratum.

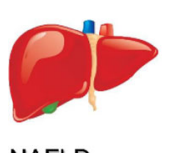

NAFLD

NASH

Liver fibrosis

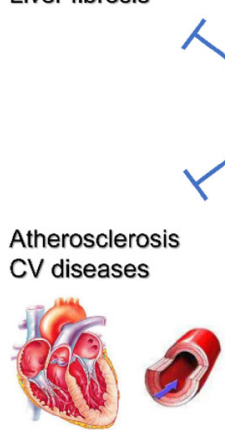

Fig. 1 Effect of DDP-4 inhibitors on the representative diabetic complications

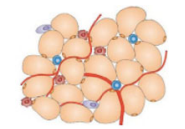

Adipocyte hypertrophy ATM accumulation

nsulin secretion $\beta$ cell mass

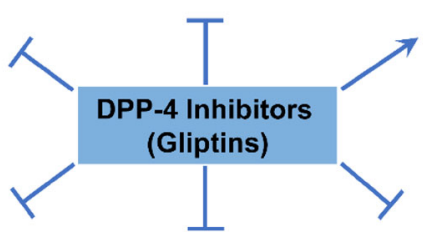

Diabetic nephropathy

Diabetic neuropathy
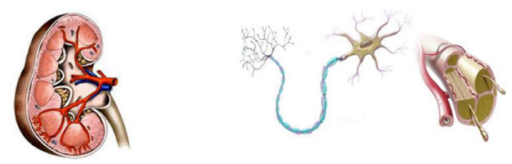

The online version of the original article can be found under doi: 10.1007/s12272-016-0813-x.

\section{Eun Ju Bae}

ejbae@woosuk.ac.kr

1 College of Pharmacy, Woosuk University, 443 Samnye-ro, Wanju, Jeonbuk 55338, Republic of Korea 